\title{
Trace conditioning with $X$-rays as an aversive stimulus
}

\author{
JAMES C. SMITH AND DAVID L. ROLL \\ FLORIDA STATE UNIVERSITY, TALLAHASSEE, FLORIDA
}

An aversion to saccharin flavored water (.1\%) was conditioned in male albino rats using $X$-rays as the noxious stimulus. The time interval between CS (saccharin) and US (X-ray) was varied for different groups and it was noted that an aversion could be formed when these stimuli were separated by as much as $12 \mathrm{~h}$. Additional groups were run with $4 \%$ sucrose as the $C S$ and the maximum effective time interval between $C S$ and US was approximately $6 h$.

It has been demonstrated that a postexposure aversion to saccharin flavored water can be conditioned in rats if the Ss are allowed to sample the sweetened water before, during, or after an exposure to ionizing radiation (e.g., Kimeldorf \& Hunt, 1965). In terms of a classical conditioning design, the saccharin solution served as the CS and the irradiation as the noxious US.

This aversion has been produced where the sampling of the saccharin (CS) followed the X-ray exposure (US) by as much as two hours (Morris \& Smith, 1964), indicating that some noxious aspect of the exposure probably lasts for several hours after termination of the $\mathrm{X}$-ray beam. In most of these studies, the preference test was initiated $24 \mathrm{~h}$ after the irradiation and only Ss which had saccharin paired with $\mathrm{X}$-ray avoided the saccharin during the preference test. Control Ss which received water or an empty bottle during exposure showed marked preference for the saccharin solution. If, however, the preference test was started immediately following exposure, all Ss developed a pronounced aversion to saccharin, regardless of whether there was saccharin, water, or an empty bottle present during exposure (e.g., Smith \& Schaeffer, 1967). The saccharin available during the immediate preference test in this experiment served as a CS. It was ingested at high rates soon after exposure but later was abandoned completely.

Aversion to saccharin has also been produced where the sampling of saccharin (CS) preceded the X-ray exposure in a trace conditioning design (McLaurin \& Scarborough, 1963; McLaurin, 1964). In these studies, however, the preference test was initiated immediately after exposure, and even the control groups which received water $3 \mathrm{~h}$ prior to X-rays, avoided the saccharin during the test. Using McLaurin's (1964) design, the saccharin could be presented at any time prior to exposure, or indeed not presented at all, and all Ss would develop the aversion to saccharin since the saccharin was available during the preference test so soon after exposure. To illustrate this point, 30 male albino rats were given saccharin flavored water for $20 \mathrm{~min}$. Twentyfour hours later, 22 of the $\mathrm{Ss}$ were exposed to $100 \mathrm{R}$
$\mathrm{X}$-rays and eight were sham irradiated. Immediately after exposure, the Ss were given a two-bottle preference test (water and saccharin) which lasted for $48 \mathrm{~h}$. The median saccharin intake for the sham exposed rats was $84 \%$ of the total fluld. For the Ss which received the X-rays, the median saccharin preference was only $34 \%$. A nonparametric test of difference in location (Walker \& Lev, 1953) indicated these scores differed beyond the .001 level of confidence.

The purpose of the present study was to determine the maximum time interval between saccharin ingestion (CS) and X-ray exposure (US) which results in a later saccharin aversion, where the preference test is widely separated from CS and US presentation. Since it is possible with $\mathrm{X}$-rays to condition an aversion to a number of preferred solutions such as sucrose (Smith \& Birkle, 1966), Kool Aid, chocolate milk, etc. (Bee Kimeldorf \& Hunt, 1965), it was of interest to investigate this interval between CS and US in a solution other than saccharin. Therefore the maximum time interval between sucrose ingestion and $X$-ray exposure which resulted in a subsequent sucrose aversion was also studied. Method

The Ss for this experiment were 206 male Sprague Dawley rats ranging in age from 90-120 days. They were housed in Hoeltge 11B cages and kept on ad lib chow at all times except during $\mathrm{X}$-ray or sham exposures.

The X-rays were generated by a GE $300 \mathrm{KV}$ Maxitron operated at $250 \mathrm{KV} 20 \mathrm{MA} 3 \mathrm{~mm} \mathrm{A1}$ filter, at a subject to target distance of $47 \mathrm{in}$. The Ss were irradiated in Plexiglas chambers on a rotating turntable at a dose rate of $30 \mathrm{R} / \mathrm{min}$ for a total dose of $100 \mathrm{R}$.

The Ss were gentled, housed in individual cages, and given two days of habituation training. This training consisted of a $20 \mathrm{~min}$ period of access to a water bottle each day following $24 \mathrm{~h}$ of water deprivation. The Ss were then split into 13 groups as described in Table 1. After the appropriate time delay, the Ss were placed in the Plexiglas boxes and given a sham exposure under the X-ray machine for $200 \mathrm{sec}$.

Following another $24 \mathrm{~h}$ water deprivation period, the Ss received a $20 \mathrm{~min}$ period of access to the saccharin flavored water (.1\% by weight) or sucrose ( $4 \%$ by weight) followed by the appropriate time interval and then $\mathrm{X}-\mathrm{ray}$ or sham exposure. For all Ss, the $48 \mathrm{~h}$ preference test was begun $24 \mathrm{~h}$ after exposure. For this test, a bottle containing saccharin (or sucrose) and a bottle containing water were attached to each home cage. The bottles were weighed and reversed in position midway during the $48 \mathrm{~h}$ preference test. 


\section{Results}

The saccharin (or sucrose) preference score was computed for each $S$ after the $48 \mathrm{~h}$ preference period. This score was the percent of the total liquid intake which was sweetened water. The medians for each group are presented in Fig. 1.

The Mann-Whitney test of difference in location was run for each delay condition between the X-irradiated and sham exposed Ss which received saccharin. Identical tests were run for Ss which received sucrose, and the results of these tests are presented in Table 1. Discussion

It is obvious from Fig. 1 and the statistical analysis presented in Table 1 that rats can be exposed as long as $12 \mathrm{~h}$ after saccharin intake and still show aversion to saccharin in a preference test initiated $24 \mathrm{~h}$ after exposure. These with earlier results (Smith et al, 1965) clearly demonstrate that the effects of both saccharin water ingestion (CS) and X-ray exposure (US) do not terminate at the cessation of stimulus presentation. Conditioning of an aversion to saccharin can occur if the saccharin ingestion precedes or follows the X-ray exposure by several hours.

The maximum effective interval between sucrose and exposure was only $6 \mathrm{~h}$. This interval is close to that found by Revusky (personal communication), using a similar technique with sucrose aversion. The difference between the saccharin and sucrose preferences

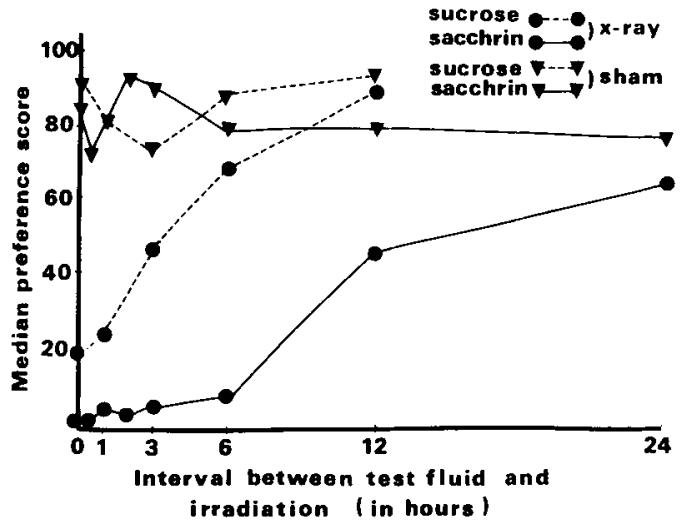

Fig. 1. The median preference score for each delay condition, exposure condition, and conditioned stimulus (saccharin or sucrose) are plotted. $\mathrm{N}=12$ for each $\mathrm{X}$-ray group and $\mathrm{N}=4$ for each sham exposed group except the $0.0 \mathrm{~h}$ delay sucrose group where $\mathrm{N}=7$ for both $\mathrm{X}$-ray and sham exposed Ss.
Table 1

\begin{tabular}{|c|c|c|c|}
\hline \multicolumn{2}{|c|}{$\begin{array}{c}\text { Time Delay Between CS Intake } \\
\text { and Exposure (In Hours) }\end{array}$} & \multicolumn{2}{|c|}{ Results of Mann-Whitney Test } \\
\hline & & Z Score & $\begin{array}{l}\text { Level of } \\
\text { Significance }\end{array}$ \\
\hline \multirow{8}{*}{ 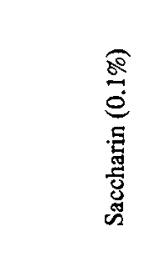 } & 0.0 & 2.92 & .002 \\
\hline & 0.5 & 2.92 & .002 \\
\hline & 1.0 & 2.92 & .002 \\
\hline & 2.0 & 2.92 & .002 \\
\hline & 3.0 & 2.92 & .002 \\
\hline & 6.0 & 2.52 & .006 \\
\hline & 12.0 & 1.45 & .073 \\
\hline & 24.0 & .85 & .200 \\
\hline \multirow{5}{*}{ 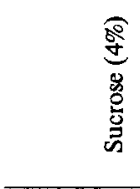 } & 0.0 & 2.43 & .008 \\
\hline & 1.0 & 1.94 & .026 \\
\hline & 3.0 & 1.45 & .073 \\
\hline & 6.0 & 1.70 & .045 \\
\hline & 12.0 & .85 & .200 \\
\hline
\end{tabular}

may be due to a difference in the time for the two fluids to clear the system, or may reflect a difference in the novelty of the two. Further experiments are in progress to study these differences.

\section{References}

KIMELDORF, D. J., \& HUNT, E. L. Ionizing radiation: Neural function and behavior. New York: Academic Press, 1965.

McLAURIN, W. A. Post-irradiation saccharin avoidance in rats as a function of the interval between ingestion and exposure. J. comp. physiol. Psychol, 1964, 57, 316-317.

MORRIS, D. D., \& SMITH, J. C. X-ray conditioned saccharin aversion induced during the immediate postexposure period. Radiation Res, 1964, 21, 513-519.

REVUSKY, S. H. Personal communication. U. S. Army Medical Research Laboratory, Fort Knox, Kentucky.

SMITH, J. C., \& BIRKLE, R. A. Conditioned aversion to sucrose in rats using X-rays as the unconditioned stimulus. Psychon. Sci., 1966, 5, 271-272.

SMITH, J. C., \& SCHAEFFER, R. W. Development of water and saccharin preferences after simultaneous exposures to saccharin solution and gamma rays. J. comp. physiol. Psychol., 1967, 63, 434-438.

SMITH, J. C., TAYLOR, H. L., MORRIS, D. D., \& HENDRICKS, J. Further studies of X-ray conditioned saccharin aversion during the postexposure period. Radiation Res, 1965, 24, 423-431.

WALKER, H. M., \& LEV, J. Statistical inference. New York: Henry Holt and Company, 1953. P. 434.

\section{Note}

1. Supported by Contracts No. AT-(40-1)-2903 and AT-(40-1)02690 with the Division of Biology and Medicine, U. A. Atomic Energy Commission. 